\title{
Impact of Social Needs Navigation on Utilization Among High Utilizers in a Large Integrated Health System: a Quasi-experimental Study
}

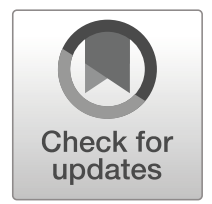

\author{
Adam Schickedanz, MD, $P h D^{7}$, Adam Sharp, MD, MS $S^{2,3}$, Yi R. Hu, MS ${ }^{2}$, \\ Nirav R. Shah, MD, MPH'4, John L. Adams, PhD'2, Damon Francis, MD ${ }^{5}$, and Artair Rogers, \\ $M S^{5,6}$
}

\begin{abstract}
'Department of Pediatrics, David Geffen School of Medicine at UCLA, Los Angeles, CA, USA; ${ }^{2}$ Research and Evaluation Department, Kaiser Permanente Southern California, Pasadena, CA, USA; ${ }^{3}$ Department of Emergency Medicine, Kaiser Permanente Los Angeles Medical Center, Los Angeles, CA, USA; ${ }^{4}$ Stanford University Clinical Excellence Research Center, Stanford, CA, USA; ${ }^{5}$ Health Leads, Boston, MA, USA; ${ }^{6}$ Kaiser Permanente Southern California, Pasadena, CA, USA.
\end{abstract}

BACKGROUND: Programs addressing social determinants of health for high-utilizing patients are gaining interest among health systems as an avenue to promote health and decrease utilization.

OBJECTIVE: To evaluate impacts of a social needs screening and navigation program for adult predicted high utilizers on total medical visit utilization.

DESIGN: A prospective, quasi-experimental study using an intent-to-treat propensity-weighted difference-indifferences approach. Stratified analyses assessed intervention effects among three low-socioeconomic status sub-samples: patients in low-income areas, in loweducation areas, and with Medicaid insurance.

PARTICIPANTS: Predicted high utilizers-patients predicted to be in the highest 1\% for total utilization in a large integrated health system.

INTERVENTION: A telephonic social needs screening and navigation program.

MAIN MEASURES: Primary difference-in-difference analyses compared total visit count utilization, including outpatient, emergency department (ED), and inpatient utilization, between the intervention and control groups at both in-network and out-of-network facilities. Prevalence of social needs among sample patients and their connection rates to social needs resources are also described.

KEY RESULTS: The study included 34,225 patients (7107 intervention, 27,118 control). Most (53\%) patients screened reported social needs, but only a minority (10\%) of those with a need were able to connect with resources to address these needs. Primary analysis found total utilization visits decreased $2.2 \%$ (95\% CI $-4.5 \%, 0.1 \% ; p=$ 0.058) in the intervention group. Stratified analyses showed decreases in total utilization for all lowsocioeconomic status subgroups receiving the intervention compared with controls: $-7.0 \%$ (95\% CI - 11.9\%, - 1.9\%; $p=0.008)$ in the low-income area group, $-11.5 \%(-17.6 \%$,

Prior Presentation This work has not been presented at conferences or in prior published manuscripts.

Electronic supplementary material The online version of this article (https://doi.org/10.1007/s11606-019-05123-2) contains supplementary material, which is available to authorized users.

Published online June 21, 2019
$5.0 \% ; p<0.001)$ in the low-education area group, and $12.1 \%(-18.1 \%,-5.6 \% ; p<0.001)$ in the Medicaid group. CONCLUSIONS: Social needs navigation programs for high-utilizing patients may have modest effects on utilization for the population overall. However, significant decreases in utilization were found among lowsocioeconomic status patients more likely to experience social needs.

KEY WORDS: social determinants of health; high utilizers; social needs; health care utilization.

$\mathrm{J}$ Gen Intern Med 34(11):2382-9

DOI: $10.1007 / \mathrm{s} 11606-019-05123-2$

(c) Society of General Internal Medicine 2019

\section{INTRODUCTION}

Health systems are increasingly interested in addressing the social determinants of health in their patient populations. The National Academy of Medicine has identified this as a vital direction for US health care. ${ }^{1,2}$ Social needs screening and navigation programs help identify patients with basic social needs (such as food insecurity, housing insecurity, and inability to afford other basic needs) in order to connect those patients with services to resolve those needs. ${ }^{3,4}$ Access to such programs is expanding rapidly, especially in health systems that serve low-income communities. ${ }^{5,6}$ Solutions to "upstream" social determinants of health for high-utilizing patients may be both an avenue for health promotion and increased efficiency. Accordingly, health system leaders, public and private payers, and public health innovators are testing a wide variety of social needs interventions focused on highcost patients. ${ }^{7-9}$ While addressing the ills of social needs is justification enough for providing these programs, ${ }^{10}$ there is also reason to believe that they may also reduce care utilization among high-utilizing, medically and socially complex patients. ${ }^{11,12}$ Enthusiasm for social needs interventions has been further driven by studies on social needs programs that reduced utilization for high utilizers, but these studies often have 
been limited in size, lack control groups to avoid regression to the mean in their results, typically focus on interventions in food and housing insecurity domains, involve intensive inperson case management, and are largely performed in safety net health systems. ${ }^{13-15}$

In this prospective study, we evaluate the effects of a telephonic social needs screening, referral, and navigation program on total health care visit utilization among insured patients predicted to have high utilization in a large, nonprofit integrated health system compared with propensity scoreweighted controls. We examine program effects among lowsocioeconomic status subgroups, including groups from lowincome areas, from low-education neighborhoods, and with Medicaid insurance coverage. We describe rates of various social needs in the group of predicted high utilizer patients participating in the program, as well as patient rates of participation and program process outcomes.

\section{METHODS}

\section{Setting and Participants}

We conducted a prospective intent-to-treat propensityweighted difference-in-differences study of the impact of a social needs intervention on health care utilization. Our study was conducted for patients in the Kaiser Permanente Southern California (KPSC) health system between November 2015 and December 2016. The large integrated KPSC health care delivery system provides health care to more than 4 million members that reflect the demographics of Southern California. To design the social needs intervention, KPSC worked in partnership with Health Leads, a non-profit organization. Routine operations collected utilization data for encounters at 13 medical centers, as well as claims data for health care utilization outside of the Kaiser Permanente network. Health Leads collected the social needs screening and navigation information in a separate database. Data from both sources were combined at the individual participant level for analyses.

Our study population included all adult patients predicted to be in the top $1 \%$ of health care utilization in KPSC. As opposed to using prior utilization alone to identify intervention patients, focusing on this population of predicted high utilizer patients (PHUPs, whose utilization is predicted to peak during the study period based on a prediction algorithm using administrative data) was intended to reduce regression to the mean as a source of bias in our study.

For eligibility inclusion, participants were required to be 18 years or older and predicted to be in the top $1 \%$ utilizers of health care for the 12 months following November 2015. In each of the participating medical centers, PHUPs were identified from a linear regression model using administrative data aggregated in the prior 6 months that used both care segmentation groupings (ranks 1-4) and diagnosis-based Diagnostic Cost Group (DxCG) risk scores to predict those patients expected to be the highest utilizing patients over the next 12 months. ${ }^{16,}{ }^{17}$ Intervention
PHUPs were those assigned to a primary care medical home at one of three medical centers (Kern County, Fontana-Ontario, and West Los Angeles) and controls were those predicted high utilizers from all other medical centers in KPSC.

\section{Social Needs Screening and Navigation Program}

The Health Leads program at KPSC was administered telephonically from a centralized location within KPSC offices. Up to four program associates with at least a bachelor's degree provided social needs screening and navigation, with assistance from two master's-trained supervisors. These Health Leads staff briefly reviewed electronic patient charts before attempting to phone each patient in the intervention group. The 14-question social needs screener (Online Appendix A) typically took 5-7 min to complete. If a patient screened positive for one or more unmet social need and was interested in help, the program associate performed a full intake assessment (10-15 min) for enrollment in social needs navigation. On average, for each social need identified through screening for a given PHUP, s/he was referred to two community-based resources (i.e., food banks, housing programs, or other agencies or resources tailored to address the identified social need). Program associates then provided social resources information immediately over the phone or during a follow-up call. If a patient was given sufficient resource information on the initial call and indicated that they did not require further follow-up, this was termed a "rapid resource referral," which occurred most for housing needs. Program associates followed up with enrolled patients at minimum every 2 weeks. Follow-up calls continued until the intervention patient could no longer be reached (termed "disconnection" after three unanswered calls), indicated he/she had the information needed to connect to the resources and no longer needed follow-up calls (termed "equipped"), or was confirmed to have connected with the resources provided (termed "resource connection"). The community resources were curated using software that provided case management functionality to track encounters, referrals, and outcomes. Program associates documented results of the social needs screening and navigation in encounter notes in the electronic health record with each telephone conversation.

\section{Outcome and Measures}

The outcome of interest was total utilization, which was a count of visits in emergency department, outpatient, and/or inpatient settings either within the Kaiser Permanente network or at outside, non-KPSC facilities within the study period. Secondary outcomes included sub-categories of total health care utilization counts inside and outside of KPSC facilities, as well as further sub-categories of emergency department, inpatient, and ambulatory/outpatient care visit counts. The out-ofnetwork, ambulatory/outpatient care visit sub-category included out-of-network outpatient primary care, specialty visits, and stays at skilled nursing facilities. 
Demographic covariates measured at the start of intervention included age, gender, race, marital status, income category based on census tract, education category based on census tract, a neighborhood diversity index,${ }^{18}$ and insurance type. Both baseline Charlson ${ }^{19}$ and DxCG risk scores ${ }^{20}$ were included as covariates to adjust for any associations between the outcome and study participant's prior diagnostics. Lastly, 14 months of pre-study period data was included to adjust for any existing secular trends in both the study and control groups.

\section{Analyses}

We examined the effect of the social needs screening and navigation program on health care utilization for 14 months after the program began. Preliminary descriptive statistics were calculated and tested using $\chi^{2}$ tests for categorical variables and $t$ tests for continuous variables. We used a difference-indifferences approach for our modeling with multiple negative binomial regression analysis for utilization as a count outcome and bootstrapped $95 \%$ confidence intervals. To estimate the effects of receiving the social needs program relative to not receiving the program, we weighted the control group participants with weights derived from propensity scores (PS), specifically their predicted odds of receiving the program if chosen to be part of the intervention group instead. The PS model incorporated all covariates mentioned above. We used a method that uses both weighting and covariate adjustments to control confounding. These estimates of treatment effect should be unconfounded by the adjustment variables if either the PS model or outcomes model was specified correctly. ${ }^{21}$ To the extent that either model is approximately correct, any channeling bias is reduced by this process. Additionally, we included participants as a random intercept to adjust for any intra-participant correlation $^{22}$ (see Online Appendix B for more detailed description of the analytic approach).

We reasoned that the effect of the social needs screening and navigation program on utilization would likely be greater for participants with more social needs or who were eligible for community-based resources typically referred to by the program. We therefore performed sub-sample analyses focused on low-socioeconomic status patients. To do so, we stratified our main analyses by three different measures of low socioeconomic status: low income level by census tract, low education by census tract, and Medicaid insurance. The first propensity-weighted difference-in-differences sub-sample analysis looked at the effect of the program on total utilization among those PHUPs whose home address fell into census tracts in which residents were most likely to be in the lowest income category in the health system's data warehouse (income under $\$ 34,575$ per year, or $138 \%$ of the Federal Poverty Line for a family of four in 2018 when the analyses were performed; $18 \%$ of the overall sample). The second subsample analysis included only PHUPs in census tracts where the plurality of residents had not graduated from high school (13\% of the overall sample). The third sub-sample analysis used Medicaid insurance (including Medicare-Medicaid dualeligibles) as an individual-level proxy of low income and included $11 \%$ of the overall sample. These sub-samples were largely non-overlapping, with only $47 \%$ of those in the loweducation area group also in the low-income area group.

The KPSC Institutional Review Board reviewed and approved this study. All statistical analyses were performed using SAS version 9.2 (SAS Institute).

\section{RESULTS}

The study included 34,225 patients, with 7107 included in the intervention group and 27,118 in the control group (Table 1). A majority of the overall sample patients were male with Medicare coverage and lived in census tracts where a plurality had greater than a high school education. The intervention patients were more diverse racially, less likely to be MedicareMedicaid dually insured, more likely to have commercial coverage, and more likely to live in a low-income area. Those who ultimately screened positive for social needs were more often female, more racially diverse, younger, and more often from poorer neighborhoods than either the intervention or comparison groups as a whole.

\section{Social Needs Screening}

The intervention staff reached $5783(81 \%)$ patients by phone. Of those contacted, 3721 (64\%) agreed to social needs screening and 1984 (53\%) screened positive for at least one social need (Fig. 1).

The most common social needs reported by PHUPs who were screened were financial strain (29\% of patients) and food insecurity ( $29 \%$ of patients; Table 1 ). Of those who screened positive for any of these social needs, 39\% wanted assistance addressing those needs and received navigation services. Absolute counts of social needs and their resolution are presented in Figure 2, while rates of program enrollment at the social needs level are also presented in Online Appendix C, Table C1.

\section{Utilization Effects of the Social Needs Screening and Navigation Program}

Overall the intervention group showed a utilization decline of $2.2 \%$ compared with the controls over 1 year post intervention $(p=0.058)$ (Table 2). Estimated average utilization visit counts declined by 0.06 emergency department visits, 0.08 inpatient hospitalizations, and 0.03 ambulatory visits for intervention patients compared with controls in the full study sample.

When examining the program effects on sub-samples more likely to have low income based on census tract, the social needs program showed larger effects on PHUP health care utilization during the study period. When only those PHUPs living in areas with low-income based on census tract were examined, total utilization count declined 7\% $(p=0.008)$ in 
Table 1 Sample Characteristics: Social Needs Program Group, Comparison Group, and Overall Sample of Predicted High Utilizers in a Large Integrated Health System

\begin{tabular}{|c|c|c|c|c|c|c|}
\hline \multirow[t]{2}{*}{ Patient characteristics } & \multicolumn{2}{|c|}{$\begin{array}{l}\text { Social needs } \\
\text { program group }(N= \\
7107)\end{array}$} & \multicolumn{2}{|c|}{$\begin{array}{l}\text { Comparison group } \\
(N=27,118)\end{array}$} & \multicolumn{2}{|c|}{ Overall $(N=34,225)$} \\
\hline & $N$ & $\%$ & $N$ & $\%$ & $N$ & $\%$ \\
\hline Age, mean (SD) & $67(15)$ & & $68(15)$ & & $68(15)$ & \\
\hline Female & 2962 & $41.7 \%$ & 10,751 & $39.7 \%$ & 13,713 & $40.1 \%$ \\
\hline \multicolumn{7}{|l|}{ Race/ethnicity } \\
\hline Asian & 304 & $4.3 \%$ & 2810 & $10.4 \%$ & 3114 & $9.1 \%$ \\
\hline Black & 1878 & $25.4 \%$ & 3265 & $12.0 \%$ & 5143 & $15.0 \%$ \\
\hline Hispanic & 1585 & $22.3 \%$ & 6376 & $23.5 \%$ & 7961 & $23.3 \%$ \\
\hline White & 3111 & $43.8 \%$ & 13,933 & $51.4 \%$ & 17,044 & $49.8 \%$ \\
\hline Other/unknown & 229 & $3.2 \%$ & 734 & $2.7 \%$ & 963 & $2.8 \%$ \\
\hline \multicolumn{7}{|l|}{ Marital status } \\
\hline Partnered & 3896 & $54.8 \%$ & 15,807 & $58.2 \%$ & 19,703 & $57.6 \%$ \\
\hline Non-partnered & 2821 & $39.7 \%$ & 11,025 & $40.8 \%$ & 13,846 & $40.5 \%$ \\
\hline Other/unknown & 390 & $5.5 \%$ & 286 & $1.0 \%$ & 676 & $2.0 \%$ \\
\hline \multicolumn{7}{|l|}{ Insurance } \\
\hline Medicare & 4255 & $59.9 \%$ & 16,243 & $59.9 \%$ & 20,498 & $59.9 \%$ \\
\hline Medicaid & 344 & $4.8 \%$ & 1254 & $4.6 \%$ & 1598 & $4.7 \%$ \\
\hline Dual & 406 & $5.7 \%$ & 2055 & $7.6 \%$ & 2461 & $7.2 \%$ \\
\hline Commercial & 1873 & $26.4 \%$ & 6613 & $24.4 \%$ & 8486 & $24.8 \%$ \\
\hline Self-pay & 151 & $2.1 \%$ & 673 & $2.5 \%$ & 824 & $2.4 \%$ \\
\hline Missing & 78 & $1.1 \%$ & 280 & $1.0 \%$ & 358 & $1.0 \%$ \\
\hline Charlson score, mean (SD) & $7(3)$ & & $7(3)$ & & $7(3)$ & \\
\hline DxCG score, mean (SD) & $25(12)$ & & $25(13)$ & & $25(13)$ & \\
\hline Cancer Dx & 2837 & $39.9 \%$ & 12,883 & $47.5 \%$ & 15,720 & $45.9 \%$ \\
\hline Diabetes & 992 & $14.0 \%$ & 3296 & $12.2 \%$ & 4288 & $12.5 \%$ \\
\hline $\mathrm{CAD} / \mathrm{CHF}$ & 2308 & $32.5 \%$ & 8901 & $32.8 \%$ & 11,209 & $32.8 \%$ \\
\hline Asthma & 490 & $6.9 \%$ & 1629 & $6.0 \%$ & 2119 & $6.2 \%$ \\
\hline Depression & 451 & $6.4 \%$ & 1460 & $5.4 \%$ & 1911 & $5.6 \%$ \\
\hline Lives in low-income census tract & 1297 & $18.3 \%$ & 3640 & $13.4 \%$ & 4937 & $14.4 \%$ \\
\hline Lives in area where plurality have high school education & 6138 & $86.4 \%$ & 24,132 & $89.0 \%$ & 30,270 & $88.4 \%$ \\
\hline Diversity score, mean (SD) & & \multicolumn{2}{|l|}{$72(16)$} & \multicolumn{2}{|l|}{$73(16)$} \\
\hline Utilization, mean (Q1, Q3) & \multicolumn{2}{|c|}{$3.75(0,5)$} & \multicolumn{2}{|l|}{$3.92(0,5)$} & \multicolumn{2}{|l|}{$3.83(0,5)$} \\
\hline Social needs assessed & \multicolumn{2}{|c|}{$\begin{array}{l}\text { Social needs } \\
\text { program group }\end{array}$} & \multicolumn{2}{|l|}{-} & \multicolumn{2}{|l|}{-} \\
\hline Financial strain & 1088 & $29.2 \%$ & \multicolumn{2}{|l|}{ - } & \multicolumn{2}{|l|}{ - } \\
\hline Food insecurity & 1076 & $28.9 \%$ & \multicolumn{2}{|l|}{-} & \multicolumn{2}{|l|}{-} \\
\hline Utilities affordability & 718 & $19.3 \%$ & \multicolumn{2}{|l|}{-} & \multirow{2}{*}{\multicolumn{2}{|c|}{-}} \\
\hline Social isolation & 714 & $19.2 \%$ & - & & & \\
\hline Affordability of medical care & 648 & $17.4 \%$ & - & & - & \\
\hline Transportation problems & 643 & $17.3 \%$ & - & & - & \\
\hline Low health literacy & 599 & $16.1 \%$ & - & & - & \\
\hline Public benefits navigation & 375 & $10.1 \%$ & - & & - & \\
\hline Housing condition concerns & 354 & $9.5 \%$ & - & & - & \\
\hline Need for financial counseling & 280 & $7.5 \%$ & - & & - & \\
\hline Housing insecurity/homelessness & 208 & $5.6 \%$ & - & & - & \\
\hline Employment/adult education & 203 & $5.4 \%$ & - & & - & \\
\hline Medical caregiver support & 201 & $5.4 \%$ & - & & - & \\
\hline Home safety concerns & 169 & $4.5 \%$ & - & & - & \\
\hline Parenting support & 78 & $2.1 \%$ & - & & - & \\
\hline
\end{tabular}

the intervention group compared with controls, driven by decreased inpatient utilization (Table 2). In a different subsample of PHUPs most likely to have the lowest rates of high school education based on census tract, total utilization counts declined $11.5 \%(p<0.001)$, driven by changes in out-ofnetwork utilization. Among PHUPs who were covered by Medicaid, total utilization count declined just over $12 \%$ $(p<0.001)$, also largely due to fewer out-of-network visits.

\section{DISCUSSION}

This telephonic social needs screening and navigation program for predicted high utilizers in a large integrated health system showed a statistically equivocal decline in overall health care utilization, but larger, significant declines in utilization were seen among sub-samples with lower socioeconomic status, including those with Medicaid coverage. Furthermore, less out-of-network utilization was observed in certain subgroups receiving the intervention. Over half of PHUPs were reached by the telephonic program and agreed to screening. Over half of those who agreed to be screened reported a social need, with the most common social needs identified being financial strain and food insecurity.

Patients from low-income and low-education areas showed greater decreases in overall utilization than the intervention group as a whole, relative to controls. This is consistent with the notion that many social needs have economic hardship and social marginalization as their root cause, and many social needs resource agencies have means-tested eligibility criteria 


\begin{tabular}{|c|c|c|c|c|c|c|c|c|c|c|}
\hline \multirow[t]{2}{*}{$\begin{array}{l}\text { 1. Patients } \\
\text { Identified }\end{array}$} & $\begin{array}{l}1 \\
1 \\
1\end{array}$ & \multirow[t]{2}{*}{$\begin{array}{l}\text { 2. Telephonic } \\
\text { Outreach }\end{array}$} & $\begin{array}{l}\text { T } \\
\text { I } \\
\text { I }\end{array}$ & \multirow[t]{2}{*}{$\begin{array}{l}\text { 3. Offer } \\
\text { Screening }\end{array}$} & \multicolumn{2}{|r|}{$\begin{array}{l}\text { 4. Social Needs } \\
\text { Screening Done }\end{array}$} & \multirow{2}{*}{\multicolumn{2}{|c|}{$\begin{array}{l}\text { 5. Enrollment in } \\
\text { Navigation }\end{array}$}} & i & \multirow[t]{2}{*}{$\begin{array}{l}\text { 6. Navigation } \\
\text { Outcome }\end{array}$} \\
\hline & $T$ & & $T$ & & $T$ & & & & $T$ & \\
\hline \multirow{20}{*}{$\begin{array}{l}\text { All patients } \\
\text { in social } \\
\text { needs } \\
\text { program } \\
(\mathrm{n}=7107)\end{array}$} & ! & Answered & I & Accepted & 1 & $\begin{array}{c}\text { Screened } \\
\text { positive }\end{array}$ & I & $\begin{array}{c}\text { Enrolled } \\
(\mathrm{n}=\mathbf{8 3 5}, \mathbf{4 8 \%})\end{array}$ & I & $\begin{array}{c}\text { Any connection } \\
(\mathrm{n}=647,77 \%)\end{array}$ \\
\hline & i & outreach & i & screening & 1 & $(n=1984,53 \%)$ & $i$ & & 1 & No connection \\
\hline & i & $(\mathrm{n}=5783$ & i & $(\mathrm{n}=3721$, & 1 & & i & & I & $(n=188,23 \%)$ \\
\hline & । & & 1 & & I & & I & Declined & 1 & \\
\hline & 1 & & I & & I & & 1 & $(\mathrm{n}=1149,52 \%)$ & I & \\
\hline & 1 & & I & & I & & I & & I & \\
\hline & 1 & & I & & 1 & Screened & I & & I & \\
\hline & I & & I & & I & negative & 1 & & I & \\
\hline & I & & I & & I & $(n=1737,47 \%)$ & I & & I & \\
\hline & I & & 1 & & I & & 1 & & 1 & \\
\hline & 1 & & I & Declined & I & & 1 & & I & \\
\hline & I & & I & screening & I & & I & & 1 & \\
\hline & I & & I & $(n=2062,36 \%)$ & I & & I & & I & \\
\hline & I & & 1 & & I & & I & & I & \\
\hline & I & & I & & I & & I & & I & \\
\hline & I & & I & & I & & 1 & & 1 & \\
\hline & I & No answer & I & & 1 & & 1 & & I & \\
\hline & 1 & $(n=1324,19 \%)$ & 1 & & I & & 1 & & 1 & \\
\hline & I & & I & & 1 & & 1 & & I & \\
\hline & ' & & I & & I & & ' & & I & \\
\hline
\end{tabular}

Figure 1 Social needs screening and navigation program steps. Participation proportions in parentheses and pathways to scale according to absolute patient volume. Authors' analyses of patient level social needs data from Kaiser Permanente Southern California patients using webbased Sankey diagram visualization (http://sankeymatic.com/build).

for receipt of services. Therefore, low-income patients would be expected to not only have more social needs influencing their health and care utilization but would also be more likely to be eligible for services to address those needs.

The pattern of utilization declines for low-socioeconomic status sub-samples was consistent even across different lowsocioeconomic status sub-samples. For PHUPs with Medicaid coverage and those with the highest likelihood of low education based on census tract, the largest changes in health care utilization were seen in out-of-network ambulatory visits, which include outpatient care and skilled nursing facility stays outside of the integrated health system. Reductions in skilled nursing facility stays have been shown in prior published social needs observational and intervention studies. In

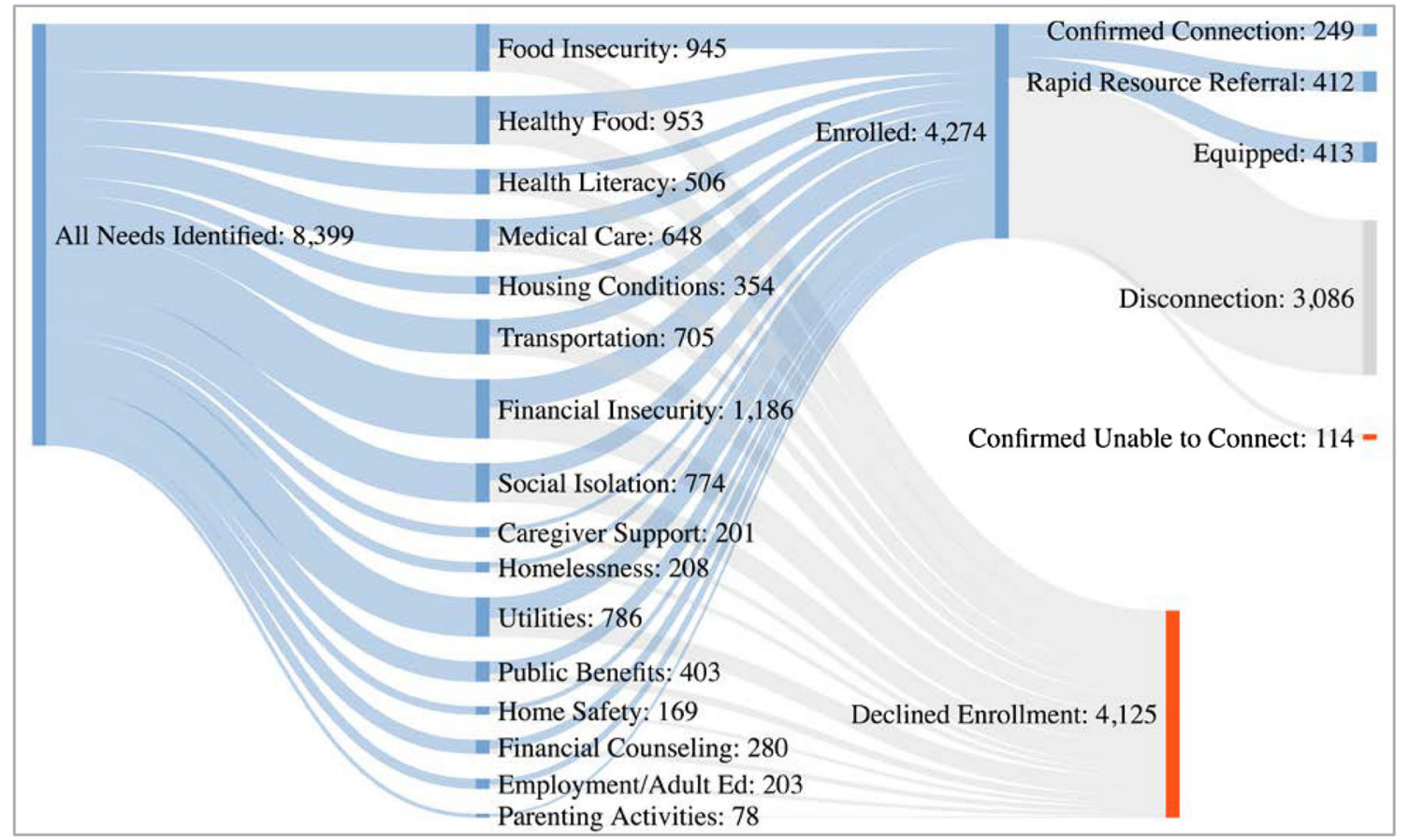

Figure 2 Social needs identified, enrollment uptake by social needs, and resolution. Pathways to scale according to absolute frequency. Authors' analyses of social need level social needs data from Kaiser Permanente Southern California patients using web-based Sankey diagram visualization (http://sankeymatic.com/build). 


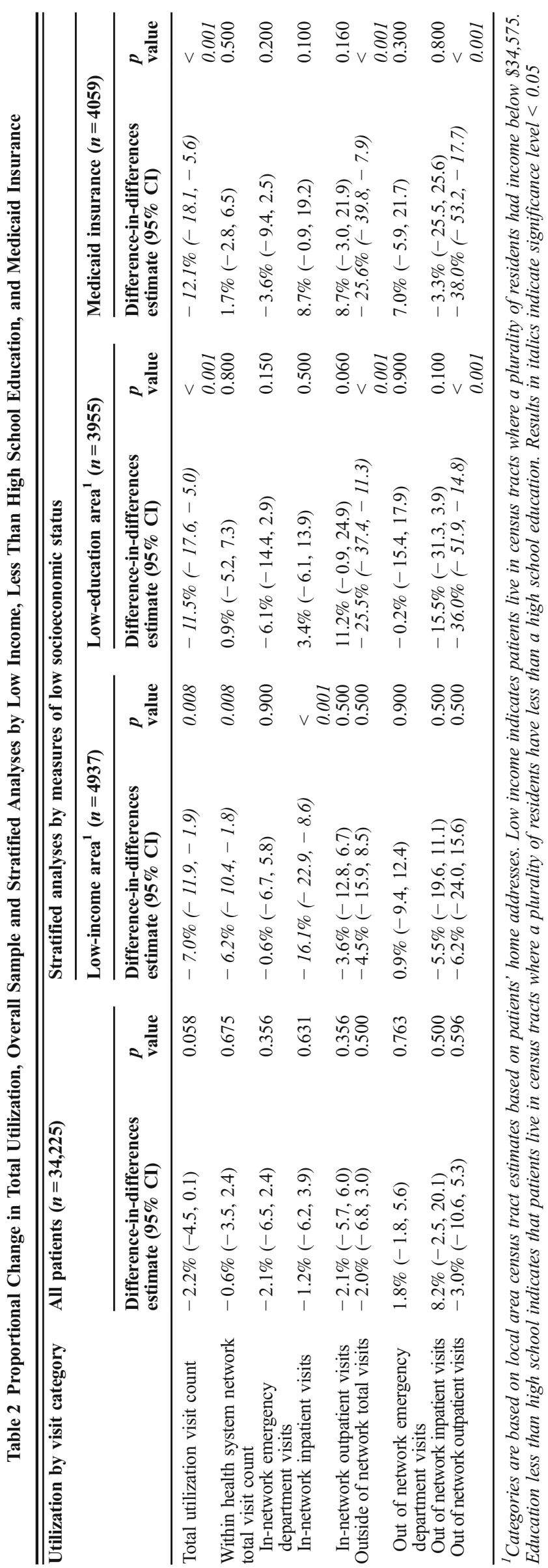


particular, food assistance programs and delivered meals have been shown to reduce nursing home admissions. ${ }^{23,}{ }^{24}$ Social isolation, a need that was addressed through our intervention, has also been linked to much higher rates of post-acute care in rehabilitation facilities. ${ }^{25}$ Nursing home admissions among socially and medically complex Medicaid patients are known to be particularly sensitive to interventions and services that help patients live independently at home and connect with community resources. ${ }^{26,27}$ These and other social factors associated with skilled nursing and rehabilitation visits may have been ameliorated through the social needs program in this study. Inpatient stays declined in the low-income PHUP sub-group analyses as well.

This is the first large study to show that a completely telephonic approach to social needs screening and navigation is feasible and produces rates of social needs identification and resource connection similar to in-person approaches. ${ }^{28}$ The call center approach was chosen for its efficiency and offers the potential for substantial cost savings compared with inperson approaches. Similar to other social needs navigation interventions, the program described in this study ultimately connected many fewer patients to social needs resources than screened positive. ${ }^{28}$ Large step-offs in patient engagement were noted at the initial contact step and when inviting patients to participate in screening. The largest step-off in patient engagement, however, was seen after PHUPs with social needs were referred to resources. Possible barriers to connecting with resources, such as competing medical issues, lack of readiness, or having already exhausted identified services, deserve future study.

Our study sample of insured patients demonstrates that even in a large commercial health system, a sizable proportion of patients have social needs. ${ }^{29,} 30$ These rates of social needs provide good evidence of the high degree of social complexity, in addition to medical complexity, found among high-utilizing patient populations.

Given the relatively small proportion of PHUPs who took part in navigation through the social needs program, it is worth considering whether there were other effects of the program that may have influenced utilization in low-socioeconomic groups in particular. At least one other rigorously designed study of a social needs navigation program has also found that even those patients who did not connect to community resources also reported health improvements. ${ }^{31}$ It may be that exploring patients' stressful life circumstances and expressing concern and empathy have a measurable effect on health and care-seeking behavior, ${ }^{32}$ or it may be that helping patients identify social needs through screening prompts them to identify their own solutions apart from those offered during the referral and navigation process. It is also possible that documenting social needs in patients' charts may have informed and influenced health care provider behavior in ways that changed utilization. Future studies should study these collateral benefits of social needs programs.

\section{Limitations}

We chose not to specifically consider effects of the program narrowly on only those who participate in navigation because of the high likelihood of introducing selection bias. Effects are likely to be artificially larger within this group, since those who have the capacity to tackle their social needs would likely also be more fit to improve their health and reduce health care utilization. It is not clear whether differences in insurance options for low-income patients may have affected or moderated utilization differences. Differences across study medical centers with respect to community resource landscape, concurrent high utilizer programs of which we were not aware, and capacity to handle social needs were not assessed but could have affected the success of the program. Our estimates of the impact of a social needs screening and navigation program may not generalize to other health systems adopting similar programs or reflect their long-term impacts.

As health systems and payers consider how to address social needs among high utilizers, our study indicates that social needs screening and navigation programs can reduce total utilization among high-utilizing patients with low socioeconomic status. The program we studied offers practical lessons to other health systems, such as demonstrating efficiencies possible through telephonic outreach and highlighting the importance of maintaining patient engagement from initial contact through resource connection. In all, our findings indicate that social needs programs are more likely to benefit patients from low-socioeconomic status areas or on Medicaid, with implications for payers and health systems working to address social needs. The end goal may be social needs programs offered based on patients' social circumstances rather than universally.

Acknowledgments: The authors wish to thank the patients of Kaiser Permanente for the use of information collected through the electronic health record.

Corresponding Author: Adam Schickedanz, MD, PhD; Department of Pediatrics David Geffen School of Medicine at UCLA, 10960 Wilshire Blvd., Suite 960, Los Angeles, CA 90024, USA (e-mail: Aschickedanz@mednet.ucla.edu).

\section{Compliance with Ethical Standards:}

Conflict of Interest: The authors declare that they do not have a conflict of interest.

\section{REFERENCES}

1. Adler NE, Glymour MM, Fielding $\mathbf{J}$. Addressing social determinants of health and health inequalities. JAMA. 2016;316(16):1641-1642. DOI: https://doi.org/10.1001/jama.2016.14058.

2. Institute of Medicine (US). Committee on the Recommended Social and Behavioral Domains and Measures for Electronic Health Records. Capturing Social and Behavioral Domains and Measures in Electronic Health Records: Phase 2. National Academies Press; 2014.

3. Fierman AH, Beck AF, Chung EK, et al. Redesigning health care practices to address childhood poverty. Acad Pediatr. 2016;16(3 Suppl):S136-146. DOI: https://doi.org/10.1016/j.acap.2016.01.004.

4. LaForge $\mathbf{K}$, Gold $\mathbf{R}$, Cottrell $\mathbf{E}$, et al. How 6 organizations developed tools and processes for social determinants of health screening in primary 
care: An overview. J Ambul Care Manage. 2018;41(1):2-14. DOI: https:// doi.org/10.1097/JAC.0000000000000221.

5. Gottlieb LM, Wing $\mathbf{H}$, Adler NE. A systematic review of interventions on patients' social and economic needs. Am J Prev Med. 2017; 53(5):719729. PMID: 28688725 DOI: https://doi.org/10.1016/j.amepre.2017.05. 011.

6. Magnan, S. 2017. Social determinants of health 101 for health care: five plus five. NAM Perspectives. Discussion Paper, National Academy of Medicine, Washington, DC. Accessed March 28, 2019: https://nam.edu/ social-determinants-of-health-101-for-health-care-five-plus-five

7. Smith KW, Bir A, Freeman NL, Koethe BC, Cohen J, Day TJ. Impact of health care delivery system innovations on total cost of care. Health Aff (Millwood). 2017;36(3):509-515. DOI: https://doi.org/10.1377/hlthaff. 2016.1308.

8. Alley DE, Asomugha CN, Conway PH, Sanghavi DM. Accountable Health Communities-addressing social needs through Medicare and Medicaid. N Engl J Med. 2016;374(1):8-11. DOI: https://doi.org/10. 1056/NEJMp1512532.

9. Gottlieb L, Colvin JD, Fleegler E, Hessler D, Garg A, Adler N Evaluating the accountable health communities demonstration project. J Gen Intern Med. 2017;32(3):345-349. DOI: https://doi.org/10.1007/ s11606-016-3920-y.

10. Garg A, Butz AM, Dworkin PH, Lewis RA, Thompson RE, Serwint JR Improving the management of family psychosocial problems at lowincome children's well-child care visits: The WE CARE Project. Pediatrics. 2007;120(3):547-558. DOI: https://doi.org/10.1542/peds.2007-0398.

11. Szymkowiak D, Montgomery AE, Johnson EE, Manning T, O'toole TP. Persistent Super-Utilization of Acute Care Services Among Subgroups of Veterans Experiencing Homelessness. Medical care. 2017 Oct 1;55(10):893-900.

12. Berkowitz SA, Terranova J, Hill C, Ajayi T, Linsky T, Tishler LW, DeWalt DA. Meal Delivery Programs Reduce the Use Of Costly Health Care In Dually Eligible Medicare And Medicaid Beneficiaries. Health Affairs. 2018 Apr 1;37(4):535-42.

13. Lim S, Singh TP, Hall G, Walters S, Gould LH. Impact of a New York City supportive housing program on housing stability and preventable health care among homeless families. Health Serv Res. 2018, Epub ahead of print. DOI: https://doi.org/10.1111/1475-6773.12849.

14. Hunter SB, Harvey M, Briscombe B, Cefalu M. Evaluation of Housing for Health Permanent Supportive Housing Program. RAND Corporation (2017). Santa Monica, CA

15. Shannon GR, Wilber KH, Allen D. Reductions in costly healthcare service utilization: Findings from the Care Advocate Program. J Am Geriatr Soc. 2006;54(7):1102-1107. DOI: https://doi.org/10.1111/j. 1532-5415.2006.00799.x

16. Zhou YY, Wong $\mathbf{W}, \mathbf{L i} \mathbf{H}$. Improving care for older adults: a model to segment the senior population. The Permanente Journal. 2014;18(3):1821.

17. Pope GC, Kautter J, Ellis RP, et al. Risk adjustment of Medicare capitation payments using the CMSHCC model. Health Care Financ Rev. 2004; 25:119-41.

18. Fremont, Allen, Joel S. Weissman, Emily Hoch, and Marc N. Elliott, When Race/Ethnicity Data Are Lacking: Using Advanced Indirect Estimation Methods to Measure Disparities. Santa Monica, CA: RAND Corporation, 2016. Accessed March 28, 2019. https://www.rand.org/ pubs/research_reports/RR1162.html.
19. Frenkel WJ, Jongerius EJ, Mandjes-van Uitert MJ, Munster BC, Rooij SE. Validation of the Charlson Comorbidity Index in acutely hospitalized elderly adults: a prospective cohort study. Journal of the American Geriatrics Society. 2014 Feb 1;62(2):342-6.

20. Ash AS, Ellis RP, Pope GC, Ayanian JZ, Bates DW, Burstin H, Iezzoni LI, MacKay E, Yu W. Using diagnoses to describe populations and predict costs. Health Care Financing Review. 2000; $21(3): 7$.

21. Rothman KJ, Greenland S, Lash TL (2008) Modern epidemiology. Philadelphia, Pa.; London: Lippincott Williams \& Wilkins.

22. Roy, A. Estimating correlation coefficient between two variables with repeated observations using mixed effects model. Biometric J. 2006; 48: 286-301.

23. Szanton SL, Samuel LJ, Cahill R, Zielinskie G, Wolff JL, Thorpe RJ, Betley C. Food assistance is associated with decreased nursing home admissions for Maryland's dually eligible older adults. BMC geriatrics. 2017 Dec; 17(1): 162 .

24. Thomas KS, Mor V. Providing more home-delivered meals is one way to keep older adults with low care needs out of nursing homes. Health Affairs. 2013 Oct 1;32(10): 1796-802.

25. Lage DE, Jernigan MC, Chang Y, Grabowski DC, Hsu J, Metlay JP, Shah SJ. Living Alone and Discharge to Skilled Nursing Facility Care after Hospitalization in Older Adults. Journal of the American Geriatrics Society. 2018 Jan 1;66(1):100-5.

26. Felix HC, Mays GP, Stewart MK, Cottoms N, Olson M. Medicaid savings resulted when community health workers matched those with needs to home and community care. Health Aff (Millwood). 2011;30(7):1366-1374. DOI: https://doi.org/10.1377/hlthaff.2011.0150.

27. Thomas KS, Keohane L, Mor V. Local Medicaid home-and communitybased services spending and nursing home admissions of younger adults. American journal of public health. 2014 Nov; 104(11):e15-7.

28. Berkowitz S. A., Hulberg A. C., Standish S., Reznor G., \& Atlas S. J. (2017). Addressing unmet basic resource needs as part of chronic cardiometabolic disease management. JAMA internal medicine, 177(2), 244-252.

29. Phipps EJ, Singletary SB, Cooblall CA, Hares HD, Braitman LE. Food insecurity in patients with high hospital utilization. Population health management. 2016 Dec 1;19(6):414-20.

30. Berkowitz SA, Hulberg AC, Standish S, Reznor G, Atlas SJ. Addressing unmet basic resource needs as part of chronic cardiometabolic disease management. JAMA Intern Med. 2016;177(2):244-252. DOI: https://doi. org/10.1001/jamainternmed.2016.7691.

31. Gottlieb LM, Hessler D, Long $\mathbf{D}$, et al. Effects of social needs screening and in-person service navigation on child health: a randomized clinical trial. JAMA Pediatr. 2016:e162521. DOI: https://doi.org/10.1001/ jamapediatrics.2016.2521

32. Decety J., \& Fotopoulou A. (2015). Why empathy has a beneficial impact on others in medicine: unifying theories. Frontiers in behavioral neuroscience, $8,457$.

Publisher's Note Springer Nature remains neutral with regard to jurisdictional claims in published maps and institutional affiliations. 